\title{
Influence of Invasive Species on the Ecosystems
}

\author{
Chief Assist Prof. PhD Radmil Nikolov \\ University of Economics - Varna, Varna, Bulgaria \\ radmil.nikolov@gmail.com
}

\begin{abstract}
Human impacts on the ecosystems of the planet increase rapidly in last few decades. Our increasing population, and expanding levels of consumption mean that more people are consuming more of nature resources and services, reaching the limit of sustainability. The global trade is feeding this consumption, by moving a wide range of goods from one part of the world to another with ship, plane, train, or truck. One critical element in this economic globalization is the movement of organisms into new ecosystems trough trade, transport, travel and tourism. In the new ecosystems where they alien, some of these species could be harmful to native species and human economic interests.
\end{abstract}

Keywords: invasive, species, ecosystems, paulownia, sustainability

JEL Code: Q1, O1; doi:10.36997/IJUSV-ESS/2019.8.1.157

\section{Въведение}

Една от най-сериозните заплахи за околната среда в глобален мащаб е загубата на биологично разнообразие. Под влияние главно на човешките дейности, в днешно време видовете изчезват от 100 до 1000 пъти по-бързо от нормалното. В последните десетилетия почти всички екосистеми и биоразнообразието, което е част от тях, са подложени на влянието на редица негативни фактори като разрушаване на местообитания, замърсяване, свръхексплоатация и промени в климата (Национален доклад за състоянието и опазването на околната среда в Република България). Естествените граници, които са определяли местообитанията на растителни и животински видове, отдавна са нарушени вследствие на антропогенната дейност. В резултат на това в екосистемите навлизат чужди за тях „инвазивни“ видове, което може да доведе както до сериозни екологични, така и до икономически проблеми.

Всъщност можем да разглеждаме инвазивните видове като фундаментален икономически проблем - по отношение на причините за появата им, последиците свързани с тяхното установяване и разходите свързани с контрола, управлението и борбата с тях. Повечето инвазии могат да бъдат свързани с предвидими или непредвидими последици от икономическите дейности, което от своя страна означава, че се изискват и икономически решения. В същото време, основната, но не и единствена причина, поради която инвазивните видове се считат за проблем, е защото те в крайна сметка въздействат върху икономическите системи в няколко направления:

- чрез нарушаване на благосъстоянието на обществото и човека;

- чрез пряко засягане на конкретни сектори или групи, като косвено се отразяват на икономическите процеси и възможностите на икономическите субекти;

- чрез своите основни влияния, ефекти и вторични въздействия;

- поради разходите, които са необходими за тяхното управление.

В настоящото изследване ще фокусираме вниманието си върху един от многото чужди за нашата екосистема видове, а именно - дървото пауловния. Към момента той се характеризира като неинвазивен, но предвид краткия период откакто е представен по-масово в България (2008 г.), ще се опитаме да защитим тезата, че като чужд вид, пауловнията може да бъде потенциално инвазивен вид в дългосрочен план (http://paulowniabg.info/?page_id=528).

\section{1. Чужди и инвазивни видове}

„Чужди видове“ са видове, които се въвеждат в територия извън предишната или 
сегашната им естествена среда и които оцеляват там и впоследствие се размножават. „Инвазивни чужди видове“ (ИЧВ) са чужди видове, чието въвеждане и/или разпространение застрашават биологичното разнообразие. Оценката на екосистемите за хилядолетието установи, че ИЧВ въздействат на всички екосистеми (Millennium Ecosystem Assessment, 2005). Проблемът на биологичните инвазии расте с високи темпове в резултат на засилените търговски дейности. Инвазивните видове $(И В)^{1}$ влияят отрицателно на биологичното разнообразие, например като се конкурират с други организми и изменят структурата на местообитанието, с токсичността си, като образуват резервоар за паразити или пренасят патогени, като произвеждат хибриди с подобни видове или сортове, с хищничество спрямо местни организми, като изменят местната хранителна верига - например инвазивни растения изменят наличието на храни, като смущават опрашването, причиняват измирането на местни видове и въздействат на екосистемите, изменяйки потоците на енергията и храните, както и физически фактори в местообитания и екосистеми. ИВ могат да причинят задръстване на водни пътища, щети в горското стопанство, по култури и сгради, както и в градските зони. Разходите за предотвратяването, контрола и/или ликвидирането на ИВ и на щетите за околната среда и икономиката са значителни. Разходите за борбата с ИВ, макар и да са по-ниски от разходите във връзка с продължително увреждане от страна на инвазивния вид, често са високи. Тези разходи могат да се избегнат или да се сведат до минимум, ако се вземат решения за предотвратяване и спиране на въвеждането на по-ранен етап.

Инвазивната биология е идентифицирала няколко етапа, през които чуждите организми трябва да преминат, преди да бъдат оценени като инвазивни. В обобщение, има четири основни стьпки в развитието на инвазия:

- въвеждане (интродуциране);

- установяване;

- разпространение - натурализация;

- разпространение - нашествие.

Въвеждането е навлизане на чужд вид в нов район (който може да бъде местообитание, екосистема, биома, държава или дори регион на земята - където преди това не е бил местен). Този процес може да бъде умишлен-от целенасочена стопанска дейност, особено за използване например в производството на храни,селско стопанство, градинарство, горско стопанство, агролесовъдство, риболов, спортен риболов, декорация, озеленяване, домашни любимци и търговия с растения, биологичен контрол, зоологични / ботанически колекции, изследвания и др. Въвеждането може да бъде и неволно, когато един вид навлиза „случайно“ в резултат на движение с други стоки, като „стопаджии“ за други видове или дейности, във вещите на пътниците, дрехите, багажа и т.н.

Установяването - когато организмът, който е бил въведен, оцелява достатъчно дълго, за да развие популация в новата му среда, която е в състояние да се възпроизвежда. Пример може да бъде установяването на чужди видове плевели, които оцеляват в нова страна в нарушени терени като крайпътни канавки и насипи, но които не се разпространяват допълнително на други места.

Разпространение - Натурализация - когато установеното животно, растение или микроорганизъм започне да се разпространява и възпроизвеждат без никаква помощ. Той става част от естествената флора или фауна и се „съчетава“ с местните видове.

Разпространение - Нашествие (инвазия) е, когато натурализираният чужд вид се разпространява поставяйки в неизгодно положение другите видове(местни или натурализирани) и причинява нарушаване на новата му екосистема по някакъв начин.

\footnotetext{
1 Понятието „инвазивни видове“, включва понятията „чужди инвазивни видове“, което се употребява в Конвенцията за биологичното разнообразие, и „инвазивни видове с неместен произход“. Инвазивните видове се определят най-общо като видове, чието въвеждане и/или разпространение застрашават биологичното разнообразие или имат други непредвидими последици.
} 
Времето от интродуциране до инвазия може да варира значително, тъй като преминаването от един етап в друг е променлива и различна за видовете и новите местообитания или екосистеми. За някои видове времето от въвеждането до натурализацията може да е седмици или месеци, за други, като дърветата, може да са години, десетилетия или дори векове. Понякога това се нарича фаза на „установяване“,последвана от разширяване на обхвата или въздействие на новото нашествие, докато то не се консолидира и може да бъде определено като такова.

Основните характеристики които ни дават основание да смятаме даден вид за инвазивен или притежаващ потенциални качества на инвазивен, когато е попаднал в подходящи условия и екосистеми, могат да бъдат представени като комбинация от характеристики на организмите. (Elton 1958.) Те включват:

- Капацитет за бърз растеж (и така към разпространение);

- Способност за широко разпространение (чрез семена, пропагули за растенията и движение за животни);

- Голям репродуктивен капацитет - или чрез производство на много потомство (или производство на много семена/пропагули);

- Широка толерантност към околната среда - способност да издържа на широк спектьр от натиск на местообитанията;

- Ефективна конкуренция с местните видове - за храна, пространство, светлина, вода, почивка, гнездене и др.

\section{2. Икономически причини за въвеждане на чужди и инвазивни видове в екосистемите}

Инвазията на различни растителни и животински видове доста често е в следствие на комплекс от различни причини. Икономическите условия и процеси също могат да бъдат предпоставка за въвеждането на инвазивни видове в екосистемите. Тези условия и процеси, често са икономически мотивирани, например включване на инвазивни видове в различни икономически дейности, промени и фрагментация на местообитания, либерализация и слаби регулации на пазарите, експанзия на стоки и услуги и изключително нарасналата мобилност на хората. (Perrings 2000).

Когато се анализират начините и пьтищата за интродуциране на чужди и потенциално инвазивни видове в дадена екосистема, следва да бъдат разгледани причините от икономическо естество, които обуславят въвеждането и разпространението им. Най-общо можем да ги разделим на:

- Преки (директни) икономически причини - включват тези дейности, свързани с производството и потреблението, водещи до въвеждане, установяване и разпространение на потенциално инвазивни видове.

- Косвени (индиректните) икономически причини включват основните икономически фактори, поминък, пазар, цена, политика и институционални условия, които позволяват или насърчават хората да се държат по конкретни начини, които водят до въвеждане, установяване и разпространение на потенциално инвазивни видове и/или които подкопават устойчивостта на човешките и естествените системи.

Преките икономически причини - представляват широк спектьр от икономически дейности, способстващи въвеждането и с влияние върху времетраенето на различните етапи в прогресията на един вид до степен на инвазия. Доколкото въвеждането на потенциално инвазивни видове може да бъде умишлено или неволно, икономическите дейности, които пряко го причиняват, включват транспортиране и трансфер на видове в области или условия, при които те могат да станат инвазивни или да се разпространят в други области и да причинят нашествия. Примери за такива дейности могат да бъдат въвеждане на видове за 
търговски цели като:

- риби и мекотели за аквакултури и морски култури;

- нови (= чужди) видове за спортен риболов;

- селскостопански семена и култури;

- животни за месо, вълна и кожи.

Въвеждане на видове за биологичен контрол на други видове, като например:

- насекоми, акари и гъбички за биологична борба;

- бързо растящи чужди растения за възстановяване на пейзажа;

- бързо растящи растителни видове за биогорива.

Въвеждане на видове свързвани с начин на живот и за естетически цели, като например:

- екзотични домашни любимци;

- чужди и модифицирани екзотични растения и др.

Косвените икономически причини - това са икономическите сигнали, които формират поведението на хората и определят състава и характера на икономиката, влияят на вкусовете и предпочитанията на потребителите, задават цените на стоките, формират рентабилноста на производителя и относителната привлекателност на различните инвестиции, използването на земята и улесняване на пътуванията и търговията. Те включват субсидии, данъци и други фискални инструменти за насърчаване на инвестиции, търговия, производство или потреблението на определени продукти или да се стимулират дейности в конкретни сектори. Други примери са квотите за внос и правила за търговия, многостранни споразумения, както и набор от институционални и регулаторни разпоредби, при които се управляват икономическите дейности в дадена държава. Косвените причини също включват по-общия икономически контекст, като състоянието на сектори, които въвеждат или използват потенциално инвазивни видове (например селско и горско стопанство, рибарство и туризъм), в които доходите и заетостта имат някакви ограничения и силно зависят от дейности, които използват потенциално инвазивни видове.

\section{3. Пауловния като икономически феномен}

Пауловния (Paulownia) е единствения род бързорастящи дървета в сем. Paulowniaceae. Род Paulownia включва в себе си няколко вида, които имат сходни качества и за това за тях се говори под събирателното име Пауловния. Исторически, оригиналното наименование на рода e Pavlovnia, но по-късно е променено на Paulownia. Наречен е така по името на кралица Анна Павловна, дъщеря на цар Павел I Петрович. По същата причина дървото е известно още като "princess tree". В Китай наричат Пауловнията "драконово дърво", а в Япония - "кири".

Всички видове Пауловния са бързорастящи дървета. Поради тази им особенност някои от тях като Paulownia tomentosa, Paulownia elongata, Paulownia fortunei и др. се използват за промишлен добив на дървесина, биомаса, етанол, фураж, хартия и други.

Дьрвото пауловния произхожда от Китай, където е култивирана и отглеждана за стопански цели от 3000 години. Високата толерантност към различни климатични условия позволяват на видовете от род Пауловния да се отглеждат в други части на света. Редица страни като Панама, Австралия, Ирландия, Никарагуа и др. са в процес на организиране на големи проекти за производство на качествена дървесина и бързорастяща биомаса от пауловния.

Основна характеристика на пауловния е нейният бърз прираст на биомаса.При добри грижи пауловнията расте с около 3 м годишно и само за 7-10 години може да достигне 
размери, оптимални за добив на дървен материал. Напълно развитата пауловния достига височина от 9-18 м, като при идеални условиясредногодишно израстват с $2 \mathrm{M} 40 \mathrm{~cm}$. Десет годишно дърво пауловния може да достигне 30-40 см в диаметър, 10-12 м на височина и обем на дървен материал от 0.2-0.6 м3 (Бояджиева, Г., Байков, Б. (2012).

Пауловния Томентоса (Paulownia tomentosa) е интродуцирана в България през първата половина на 20-ти век. Тя се среща като единично дърво из парковите зони в редица градове на страната.

България се намира на 43 паралел от Екватора със средногодишна температура от $10,5^{\circ} \mathrm{C}$ (средна минимална $-2,0^{\circ} \mathrm{C} \mathrm{C}$ и средна максимална $24^{\circ} \mathrm{C}$ ), средна надморска височина 467 м, средна годишна сума на валежите 670 мм и преобладаващи канелено горски и черноземни почви. Около 70 \% от територията на страната ни е равнинна и хълмиста. С изключение на високопланинската територия в България съществуват подходящи условия за отглеждане на по-студоустойчиви видове и хибриди пауловния. Частични изследвания върху вегетативното размножаване и опити за клониране на Paulownia tomentosa Steud. ce провеждат в Опитна станция за бързорастящи горско дървесни видове, Свищов, от 1970 г.

По-масовото навлизане на Пауловния в България е през 2008 г. Доставени са и засадени първите 5000 броя Paulownia tomentosa като базов материал в лицензиран горски разсадник. През 2010 г. са залесени и първите терени с иновативния хибрид Paulownia shan tong (paulownia shanxi) в България и Европа ( https://www.bgfermer.bg/Article/4676526).

Най-разпространени в България са видовете Елонгата (Elongata), Томентоза (Tomentosa), Фортунай (Fortunei), Каталапафолиа (Catalapafolia), и Шанг Тонг (Shan-tong).

Ако трябва да обобщим накратко икономическите и екологични характеристики на Пауловния, довели до интродуцирането и в нашата страна и превърнали я в обект на инвестиционен интерес, то можем да ги сведем до следните:

- Дървесината на Пауловния е една от най-ценните и тьрсени на световния пазар. Използва се за строеж на къщи, в корабостроенето и самолетостроенето, за производство на мебели и изработка на фурнири, играчки, музикални инструменти и други. Тя е много лека, средното и тегло е от 208 до 282 кг. на кубичен метьр. Дървесината на Пауловния е почти четири пьти по лека от тази на дъба (850 кг/м3) и наполовина от дървесината на бора (482 кг/м3). Задържа малко влага (до 10 $12 \%)$. Светла е и поема добре боите (оцветители).

- Биомасата добивана от Пауловния се използва за производство на пелети, брикети и дървен чипс - добив на биомаса от 6 до 8 тона на декар; ротация - 2 години; калоричност $4500 \mathrm{kcal} / \mathrm{kg}$; не е необходимо презасаждане.

- Биоетанол - добив на зелена биомаса до 6 тона от декар; ротация - 1 година; не е необходимо презасаждане.

- Листата могат да се използват за фураж на животните. Имат хранителна стойност близка до тази на люцерната.

- Листата на този дървесен вид също са много ценни, размерите им достигат до 75 см. в диаметьр и са най-добрите „фабрики” за кислород. Те поемат много големи количества въглероден диоксид и освобождават големи количества кислород, като по този начин пречистват стотици хиляди куб. метри въздух. Пауловнията абсорбира 10 пъти повече въглероден диоксид, от който и да е дървесен вид.

- Пауловния е подходяща за рекултивация на сметища и унищожени от стопанска дейност терени. Укрепване на брегове на реки, борба с ерозията и др.

- Дървото е едно от най-медоносните растения и цъфти след втората година в края на месец април - началото на месец май. Излкючително подходящо за 
декоративно засаждане, озеленяване, изграждане на ветрозащитни пояси и укрепване на корозирали терени ( http://fidanki.bg).

\section{4. Потенциал за инвазивност на Пауловния}

От всичко казано дотук изглежда, че Пауловния е дървесен вид който може да даде тласьк на производството на биомаса и дървен материал, както и да реши редица други икономически и екологични проблеми, като качествата на вида го издигат до нивото на панацея в редица икономически дейности. Опазването на биоразнообразието и здравето на екосистемите обаче, изисква и един по-критичен поглед върху въвеждането на чужд за дадена територия вид.

Пауловния томентоса (един от подходящите за отглеждане в България вид) е въведен като декоративно дърво в много европейски страни и в САЩ. Този дървесен вид е донесен в Европа през 1830 г. от Холандската Източноиндийска компания, а малко по-късно в средата на 19-ти век пауловния прониква и на територията на САЩ. Семената на пауловния се използвали като опаковъчен материал при транспортирането на изящни чинии от порцелан през Тихия океан. След разопаковането отнесените от вятьра малки семенца се приспособили към средата в източните щати, където е натурализиран и по-късно се отглежда и на западния бряг (SE-EPPC, 2003).

Разпространението на дървото в Европа е първоначално в парковете като декоративно (1830 г.), с по-широко разпространение в плантации за дървен материал в Италия след 1989 г. и като ветрозащитни пояси в Средиземноморието. От 50-те години на миналия век постепенно се въвежда в Бразилия, Парагвай, Аржентина и Австралия и се използва главно за производството на дървен материал.

P.tomentosa е в списъка с инвазивни видове за щатите Кьнектикът и Тенеси, САЩ (USDA-NRCS, 2008) и показва инвазивни характеристики на други места, като в Колумбия е определен за инвазивен (https://dialogochino.net/12442-chinese-empress-tree-declared-invasivespecies-in-colombia/). Той може да стане инвазивен там, където вече е въведен в Европа и Южна Америка, но като се отбележи стойността му като бързорастящ дървен материал и декоративен вид за паркове, е много вероятно той да бъде допълнително въведен на други места, където също може да стане инвазивен. Потенциала на Пауловния да се превърне в инвазивен вид се крие в биологичните характеристики на дървото.

P. tomentosa може да се размножава от семена или от коренови издънки, като отрязано дърво може да се възстанови и да нарасне до няколко метра за един сезон. Дърветата започват да дават плодове след 8-10 години и са много плодовити, като семената се съдържат в капсули всяка съдържаща до 2000 семена. Голямо дърво, може да даде до 20 милиона семена годишно. Малките плоски крилати семена тежат около 0,17 mg и докато капсулите се отварят по дърветата през зимата и през пролетта, разпространението им по вятъра става лесно, което прави възможно разпространението им върху големи площи при подходящи условия.

По данни на Invasive Species Compendium, (https://www.cabi.org/ последен ьпдейт 31.10.2019) факторите на риска и въздействието на Paulownia tomentosa (paulownia) върху екосистемата имат следния вид:

\section{Инвазивност :}

- доказано инвазивно извън родния си хабитат;

- има широк видов състав;

- силно адаптивен към различни среди;

- толерантен (и се възползва от) към отглеждане, натиска на търсенето, сеч, пожари и т.н.; 
- пионер в нарушени и ерозирали райони;

- локално мобилен;

- дълъг жизнен цикъл;

- бързо растящ;

- висок репродуктивен потенциал;

- възпроизвежда се асексуално;

- има висока генетична вариабилност.

Резултати от въздействието:

- промяна на екосистемата / изменение на местообитанието;

- увеличава уязвимостта към инвазии;

- модификация на последователните модели;

- монокултурна формация;

- намалено местно биоразнообразие;

- заплаха за / загуба на местни видове.

\section{Механизми на въздействие:}

- конкуренция - монополизиране на ресурси;

- конкуренция - засенчване;

- взаимодействие с други инвазивни видове;

- бърз растеж.

\section{Вероятност за навлизане и контрол:}

- има голяма вероятност да бъде разпространен масово в международен план;

- трудно/скъп за контрол.

В България към днешна дата липсват точни данни за разпространието на Пауловния. Според различни източници, площите засадени за добив на дървесина и биомаса варират от няколко стотин до 1000 дка. Няколко са големите фирми, които предлагат посадъчен материал и консултации за изграждането на плантации за добив на дървесина. За разпространението на посадъчен материал, макар и бегла представа може да бъде получена ако се проследи броя на обявите за продажба (olx.bg):

- Област Пловдив (6)

- Област Монтана (1)

- Област Шумен (1)

- Област Пазарджик (4)

- Област Перник (1)

- Област Благоевград (2)

- Област Плевен (1)

- Област София-град (2)

- Област Сливен (1)

- Област Велико Търново (1)

- Област Стара Загора (1).

Пауловния без съмнение е изключително атрактивен вид, и предизвиква инвеститорски интерес със своите качества. Но също така несъмнено притежава потенциала да се превърне в инвазивен за нашата екосистема, както вече се е случвало в други страни.

Инвазивните видове водят до разходи. През 2008 г. разходите за борбата с инвазивните видове и възстановяването на щетите, които те причиняват в Европейския Съюз (ЕС), са достигнали приблизително 9,6-12,7 млрд. EUR. Но този диапазон определено е занижен поради факта, че много страни едва сега започват да изчисляват разходите. Средства по 
програма LIFE също се инвестират в проекти за справяне с инвазивните видове. От 1992 г. EC е изразходил над 38 милиона EUR по 180 проекта, както в рамките на мрежата от защитени зони на Натура 2000, така и извън нея. За сравнение - САЩ оценяват изразходваните от тях средства за борбата с биологичните нашественици на около 80 милиарда EUR годишно. Няма данни за доказана инвазивност на Пауловния в Европа, но при данните за потенциална инвазивност на вида, бихме могли да приведем пример за разходите за управление и справяне примерно на друг дървесен вид :

В Европейския съюз Acacia saligna (красиво декоративно дърво) се управлява (локално ликвидиране, контрол) от много проекти на LIFE, поради което съществува известна информация за разходите за контрол, например LIFE08NAT / IT / 000353 (9,40 евро на квадратен метър), LIFE13 NAT / IT / 000433 ( 17 000,00 евро на ха) или LIFE13 NAT / CY / 000176 (10 000,00 евро на ха цена на труда, без разходите за хербицида) (данни от Scalera et al., 2017), докато доклади от друг проект от Кипър са изчислили цената на труда на контрол от 8630 евро на ха (www.care-mediflora.eu). По същия начин оборудването и сравнителните разходи за програми за ликвидиране на Acacia nilotica в Австралия могат да бъдат намерени в ръководството на Calvert (2011), като методите за механично изчистване струват между AUD 65 до 220 (около 40 до 135 EUR) на хектар и първоначалното изчистване от 700 ха струва общо 344681 AUD (около 210780 EUR). Имайте предвид, че те не обхващат поддържането на регенерация от коренови издънки (https://circabc.europa.eu).

\section{Заключение}

По икономически причини ние внасяме видове които разнообразяват нашия ландшафт, или са обект на инвестиционен интерес но не бива да забравяме, че по-късно може да се наложи някой да плати за този ефект. Тези разходи тогава ще се прехвърлят върху икономиката и данъкоплатеца в частност.

По същество инвазиите обикновено са външните ефекти на пазарните транзакции (Perrings 2002) - където пазарните цени не отразяват точно пълните социални и икономически разходи, свързани с инвазиите. Физическото лице или компанията, които въвеждат или разпространяват потенциално инвазивните видове, обикновено не понасят разходите, свързани с тяхното въздействие върху екосистемите (въпреки че те реализират частни ползи под формата на печалба. Тези разходи се усещат повече от другите икономически субекти, като косвени загуби или пропуснати ползи. В обобщение можем да направим следните изводи:

1. В България Пауловния е чужд вид, внесен и разпространяван по преки икономически причини, за добив на дървесина и биомаса.

2. Налице са и косвени икономически причини, а именно възможността да се получават субсидии за отглеждане на енергийни култури, ако бенефициента докаже, че спазва правилата за биологично производство.

3. Видът се намира във фаза „разпространение и натурализация“.

4. Пауловния показва инвазивни характеристики, и съществува вероятност да „избяга“ от плантациите където се култивира и да се установи в ново местообитание.

5. Paulownia /Пауловния / е бързорастящ дървесен вид включен в списъка на интродуцираните видове съгласно отменената по-късно Наредба №2 от 02.02.2009 г. за залесяване и инвентаризация на горските култури в България.

6. Изглежда съществува вакуум в нормативната уредба по отношение на вида, тьй като той не се споменава нито в Закона за билогичното разнообразие, нито в Наредба № 2 от 7.02.2013 г. за условията и реда за залесяване на горски територии 
и земеделски земи, използвани за създаване на специални, защитни и стопански гори в защитени територии, инвентаризация на създадените култури и тяхното отчитане.

\section{References}

1. Boyadzhieva, G., Baykov, B. (2012). Ekologichna otsenka na energiynata kultura Paulovniya v Balgariya, Sbornik nauchni dokladi IV godishna mezhdunarodna nauchna konferentsiya „Ekologizatsiya 2012”, Sofiya, s. 34-39.

2. Calvert, G (2011). Prickly acacia eradication project. NQ Dry Tropics. Townsville, Australia, pp.27. Available from: ttp://wiki.bdtnrm.org.au/images/temp/1/1a/20131122055216!phpo XB6QQ.pdf [Accessed 17/10/2019].

3. Elton, C.S. (1958). The Ecology of Invasions by Animals and Plants. Kluwer Academic Publishers

4. McNeely, Jeffrey A. The Great Reshuffling Human Dimensions Invasive Alien Species

5. Millennium Ecosystem Assessment (2005). Ecosystems and Human Well-being: Synthesis. Island Press, Washington, DC.

6. Nakov, L. (2015). Evaluation of the effectiveness of innovation strategy for optimal biomass production of paulownia Institute of System Engineering and Robotics. Management and sustainable development. Bulgarian Academy of Sciences, Bulgaria. 6/2015 (55)

7. Perrings, C., 2000, The Economics of Biological Invasions. Paper prepared for the workshop on Best Management Practices for Preventing and Controlling Invasive Alien Species South Africa. United States of America Bi-National Commission

8. Scalera, R., Cozzi, A., Caccamo, C. \& Rossi, I. (2017). A catalogue of LIFE projects contributing to the management of alien species in the European Union. Platform Meeting on Invasive Alien Species (IAS) 29-30 November 2017, Milan (Italy). LIFE14 IP/IT/000018 Nature Integrated Management to 2020 (GESTIRE 2020), 140 pp.

9. USDA-NRCS (2008). The PLANTS Database. Baton Rouge, USA: National Plant Data Center. Available from: http://plants.usda.gov [Accessed 17/10/2019].

10. https://circabc.europa.eu/faces/jsp/extension/wai/navigation/container.jsp

11. https://dialogochino.net/12442-chinese-empress-tree-declared-invasive-species-in-colombia/

12. http://fidanki.bg

13. https://www.invasive.org/browse/subinfo.cfm?sub=2426

14. http://paulowniabg.info/?page_id=528

15. https://www.bgfermer.bg

16. https://www.cabi.org/isc/abstract/20087203993

17. https://www.cabi.org/isc/datasheet/39100\#tosummaryOfInvasiveness

18. https://www.eddmaps.org/ipane/ipanespecies/trees/Paulownia_tomentosa.htm 